\title{
Application and Practice of Case Teaching in Environmental Monitoring Course
}

\author{
Jing-Ping Wang, Zheng-Hao Fei, Xin-Hong Wang, Jian Chen, Zong-Tang Liu \\ School of Chemical and Environmental Engineering, Yancheng Teachers University, \\ Jiangsu, 224007, China,
}

The research is supported by a Project Funded by the brand professional project form Yancheng teachers college (2016) and the teaching reform and practice of medicinal chemistry (2018YCTUJGY006) and the Flagship Major Development of Jiangsu Higher Education Institutions"(PPZY2015B113)。

\begin{abstract}
The environmental monitoring course "is a practical and comprehensive university environment related strong professional required courses. In this paper, case teaching method is applied in the teaching process of environmental monitoring course, which provides a wide value space for the development of practical ability of environmental undergraduates, and at the same time Narrows the gap between theory and practice, facilitates the comprehensive application of environmental professional knowledge to solve environmental problems, and provides an effective way for the diversification and independent innovation of environmental undergraduates. The results show that case teaching can stimulate students' interest in learning, activate classroom atmosphere, and improve students' ability to analyze and solve practical environmental monitoring problems.
\end{abstract}

Keywords: Case teaching; Environmental monitoring; Teaching practice

DOI: $10.7176 / J E E S / 9-11-11$

Publication date: November $30^{\text {th }} 2019$

\section{Introduction}

Case teaching appeared in Harvard University in 1870 and has a history of more than 100 years [1]. It is an open and interactive new teaching method. As a heuristic teaching method, case teaching uses teaching cases based on real events to guide students to analyze and discuss cases so as to achieve high-level cognitive learning goals ${ }^{[2]}$. It emphasizes that take the student as the main body, in order to cultivate students' autonomous learning ability, practice ability and innovation ability as the basic value orientation, broke the embarrassing situation in theory and practice of teaching the disconnect, has unique advantages in professional course teaching ${ }^{[3]}$.

"Environmental monitoring" course is a compulsory and highly practical main course for environmental majors, which is of great significance to improve the quality of environmental professionals. Good environmental monitoring curriculum teaching, can not only make students obtain professional skills, strong environmental detection but also to promote the competitiveness of the students' employment is of great significance. But as a result of the course content covers widely, updated quickly, less class hours, the traditional curriculum teaching effect is not very ideal. he environmental talents needed in today's society need the ability to learn independently and analyze and solve practical problems. Therefore, the key direction of environmental monitoring teaching 
reform is to train the high-quality talents with the ability to analyze and solve environmental problems. The United Nations educational, scientific and cultural organization has case teaching, seminars, classroom teaching and simulation practice teaching function of nine kinds of teaching methods such as investigation, found that case teaching in training analysis ability ranks first ${ }^{[4]}$. Therefore, how to organize classroom teaching in the limited time, make the students' creativity and analysis problem, problem-solving ability, is a teacher in the teaching process must be thinking about, to explore suitable for the characteristics of "environmental monitoring" teaching mode teaching, case teaching, has become one of the environmental monitoring demand of teaching reform.

\section{Combination of theory and practice by case teaching}

Traditional teaching of "environmental monitoring" focuses on teaching the basic content of teaching materials and inculcating basic theoretical knowledge for students. It is highly practical to introduce case teaching into the teaching of "environmental monitoring" course, so as to establish teaching cases based on real environmental events that have great social impact. Through the guidance of teachers, the phenomenon of environmental pollution is analyzed, the causes of environmental pollution are discussed with the theoretical knowledge learned, and the corresponding monitoring scheme is developed. The theory and practice are put in a specific teaching situation, and the purpose of combining theoretical teaching and practice is achieved in the process of analysis and discussion [5].

The first step of case teaching is to present teaching cases. Teachers can draw out cases through PPT, video, whiteboard, scenario simulation and other means. The presentation mode of cases can be flexibly used according to the teaching content and teaching stage. In practical teaching, video and simulated situations can enhance the intuitiveness of classroom teaching, improve the participation of students, and enable students to quickly enter the case environment ${ }^{[6]}$. Early in the teaching of the course, they can introduce some enterprise project completion environmental protection acceptance monitoring report, from the basic situation of construction project, construction project survey, field into survey, collecting information and monitoring scheme, sample collection, sample test, and experimental data analysis, writing test evaluation report and the construction of project emission of waste gas, waste water, noise pollution and operation of the monitoring analysis of environmental protection treatment facilities. The purpose and content of environmental monitoring can be explained by such cases, so that students can deeply understand the determination of representative pollution factors that affect environmental quality, accurately, timely and comprehensively reflect the current situation of environmental quality (or pollution degree), provide scientific basis for environmental planning and management, pollution control and treatment, etc., and make students' understanding of knowledge points no longer stay on the surface, but can conduct in-depth comprehensive thinking. This kind of case will explain the general process of environmental monitoring, including field investigation, formulation of monitoring scheme, optimization of distribution point, sample collection, analysis and testing, data processing, and comprehensive evaluation. These trivial knowledge points will be connected together and the relevance of knowledge points will be emphasized, so that students can have a certain degree of overall understanding of the monitoring and analysis process and make it more intuitive and easier to understand. This kind of case is vividly explained the content and the steps of monitoring scheme design, collect basic data, determine the monitoring project, optimization of the sampling points, sampling time, choice of sampling method and monitoring method, the results express that enhances the students' interest in learning. 
It is highly practical to introduce case teaching into the teaching of "environmental monitoring" course, so as to establish teaching cases based on real environmental events that have great social impact. Through the guidance of teachers, the phenomenon of environmental pollution is analyzed, the causes of environmental pollution are discussed with the theoretical knowledge learned, and the corresponding monitoring scheme is developed. The theory and practice are put in a specific teaching situation, and the purpose of combining theoretical teaching and practice is achieved in the process of analysis and discussion.

\section{Enhancement of students' learning initiative by case teaching}

Case teaching is introduced into the teaching of "environmental monitoring" course. In the specific scenario setting, through the conscious guidance and inspiration of teachers, students search for materials independently, analyze the causes of events, and propose monitoring schemes and solutions, thus improving their independent learning ability $^{[7]}$. In the middle and later stages of teaching, the basic concepts, principles and methods and other important knowledge have been mentioned. The case teaching link can be strengthened to change students' mechanical memory, quietly observe the state without saying a word, let students actively participate in the class, and form teacher-student interaction. For example, when learning the chapter of surface water quality monitoring, shi haoran, zhou min and tang xiaolei, students majoring in environmental science, were introduced to participate in the "Anlailisi" water treatment competition for college students of jiangsu ordinary colleges and universities in 2016, and won the provincial special prize, the provincial first prize and the provincial second prize respectively. Its to participate in competitions for nanjing "exhibition" water quality survey and evaluation. Give students simulation scheme design, in order to strengthen environmental science professional promotion, strengthen the analysis ability, broaden the students' field of vision and optimize the environmental science major teaching, to improve environmental science majors multi-level comprehensive design and actual analysis ability. Organized group students form teams, collaboration, stimulate students' participation enthusiasm. Let students based background information, nanjing xuanwu "guide, inspire and help the students to design the water monitoring plan, encourage students to think independently, students according to the theory knowledge, can free discussion of issues, between each other advice, at the same time, strengthen the collaboration between the students. Students, from the perspective of the layout sampling point, a comprehensive grasp sample collection, preservation, preparation, pretreatment and determination of basic principle and knowledge and quality control, to cultivate the student's ability to analyze and solve practical problems in environmental monitoring. Especially on the determination of COD in Nanjing "exhibition", how to deal with the problem before the sample, the student to put forward several methods of comparison, choose feasible, the last report in the form of PPT, etc, finally summarized. This case will be applied race into the classroom, the system about the design of monitoring solution content, in view of the sample pretreatment method, the monitoring scheme for the inspection points more, it obtained the very good practice, on the analysis of the test details and matters needing attention are also very good exercise, to strengthen the communication between teachers and students, between students and students, and cultivate the students' ability of instance; This case will monitor the content of the design rules of abstract corresponds to the actual problem, deepen students' understanding of basic theoretical knowledge, and students to participate in the design, stretching out many problems, students in the face of practical problems through positive discussion, views, our subjective initiative, multi-angle thinking, the major issues of case put forward their own opinions, ideas and methods, to 
cultivate the students' ability to analyze and solve problems, to achieve the teaching purpose and requirements.

Case teaching after the student's full discussion, the teacher wants to timely summary comments, this phase is the key to the case of classroom teaching, is often a class of climax stage. Teachers should affirm students' good ideas and unique opinions, and point out the problems and shortcomings in the discussion. By analyzing the case and combining the discussion results of students, we can find out the difficult points of the case and help students clarify their thoughts. We should explore and solve the case problems from different angles and methods. At the same time, combined with the discussion results of students, teachers put forward several problems with concentrated opinions and treatment methods, organize each group to discuss these problems and treatment methods, and guide students to effectively use the knowledge they have learned to solve cases or practical problems. Finally, teachers should put forward some extended questions and thinking to further expand the scope and depth of learning.

\section{The optimal selection and design of the case teaching}

Environmental monitoring course cases are all derived from real environmental events, which are closely related to specific social, economic, historical, geographical environment and other factors. With complexity, students can analyze and judge such complex and changeable environmental problems, and their ability to solve practical problems will be improved. At the same time, case teaching generally has no fixed conclusion and its answers are open, which is more conducive to improving students' ability to analyze and solve practical environmental problems. In the process of case teaching, the selection of cases is very important. According to the training objectives and teaching objectives of this major, relevant cases that can not only integrate relevant professional knowledge, but also increase students' perceptual understanding and improve their analysis and solution of problems should be selected. he questions should be set in a hierarchical and gradual manner to ensure that they can trigger reflection, enthusiasm, resonance and controversy. Teaching time arrangement should be reasonable to ensure the smooth completion of teaching; Establish case teaching assessment system and make clear the requirements for students. In lesson preparation, student graduation thesis, combined with the article collect past graduates work in the environmental protection of employment information, sorting out some representative, targeted and typical teaching case. Such as: New campus of river basin pollution status quo analysis and quality evaluation, yancheng and renhuai people human hair mercury levels in the research, Dongfeng yueda kia, a factory of total hydrocarbon (NMHC) methane emission characteristics research, sulfide and dyeing dye production wastewater treatment study, organochlorine DDT in soil, and the 666 gas chromatography determination, etc., in water, soil, atmosphere monitoring and teaching in the more comprehensive monitoring of environmental medium, and the real cases from the practice, has the pertinence, let students experience a real case, is a vivid story, in fresh curiosity, Learned tedious theoretical knowledge. Cases of previous graduates engaged in environmental protection work choose different employment directions, such as jiangsu zhongju testing service co., LTD., taizhou environmental monitoring station, yancheng water supplies co., LTD., these cases related to environmental protection professional direction are designed to include atmospheric monitoring and analysis, water pollution treatment, environmental quality assessment and management, environmental impact assessment report writing, etc., so as to expand and deepen the teaching content, enrich the teaching content, expand students' horizon, accumulate practical experience, and make students feel that their major can be engaged in so many 
aspects of work, and enhance students' sense of professional identity. After the real cases are explained, virtual similar cases can be set up to make students think and enhance the teaching effect. Students can change from passive to active participation in person, improve students' ability to analyze problems and adapt to different situations, and cultivate their ability to understand by analogy.

\section{Conclusion}

Environmental monitoring is a professional basic course with interdisciplinary disciplines in the field of environmental science. After years of practice, the teaching content has been expanded and depth increased after the implementation of the traditional classroom teaching and case teaching combined with the emphasis on the teaching mode of case teaching method. Through the analysis and explanation of cases, the enthusiasm of each student to participate before, in class and after class has been effectively promoted, and students' interest in this course has been stimulated. Due to the limited number of class hours, case discussion is sometimes not fully implemented. It is suggested to increase the number of class hours appropriately to achieve better teaching effect of case teaching.

\section{References}

[1] Guang-fu Yang, Hong-ju Zhang. Case Teaching: From Harvard to the World - History of Case Teaching Development. Foreign Primary and Secondary Education, 2008, 24 (6): 1-5.

[2] Qing-mei Wang, Ge Zhao. A review of case teaching methods at home and abroad. Journal of Ningbo University (Educational Science Edition), 2009, 31 (3): 7-11.

[3] Gao-chen Wu, Shuang Liu. Practice Orientation: Case Teaching Method Research. Heilongjiang Higher Education Research, 2011, 17 (12): 178-181.

[4] Shan Xie, Ke Ouyang. New Measures for Teaching Process Reform of Environmental Planning and Management. Guangdong Chemical Industry, 2017, 44 (9): 272, 278.

[5] Hong-mei Deng, et al. Application of Case Teaching Method in Environmental Chemistry Course. Guangdong Chemical Industry, 2009, 36 (5): 207-209.

[6] Wen-qiong Yu. Problems and Solutions of Case Teaching Method in Practice. Educational Theory and Practice, 2011, 31 (7): 46-47.

[7] Yi-xuan Wang, et al. Evaluation of the effect of case teaching method in the teaching of Environmental Science. Guangdong Chemical Industry, 2014, 41 (22): 181-182. 